\title{
Radioiodination of Quetiapine and Cyclobenzaprine as Brain Monitoring Agents: A Comparative Study on SPECT Imaging
}

\author{
H. A. El-Sabagh ${ }^{1 *}$, M.A. Mourad ${ }^{2}$, A.M. Amin ${ }^{1}$ and S.A. Abo El-Enein ${ }^{3}$ \\ ${ }^{(1)}$ Labeled Compounds Department, Hot Labs Center, Atomic Energy Authority, Cairo, Egypt \\ (1) Professor of radiochemistry, Labeled Compounds Department, Hot Labs Center, Atomic Energy Authority, Cairo, Egypt.

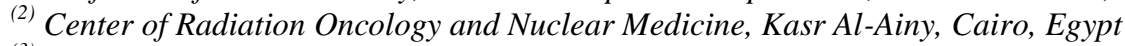 \\ (3) Chemistry Department, Faculty of Science, Ain Shams University, Cairo, Egypt
}

\begin{tabular}{l} 
ART ICLE INFO \\
\hline Article history: \\
Received: $8^{\text {th }}$ June 2020 \\
Accepted: $4^{\text {th }}$ Aug. 2020 \\
\hline Keywords: \\
Radioiodination, \\
Quetiapine, \\
Cyclobenzaprine, \\
Biodistribution, \\
Brain imaging, SPECT, CT.
\end{tabular}

\begin{abstract}
The aim of this study is to use drugs capable of crossing the blood-brain barrier (BBB) to develop new radiopharmaceuticals for non-invasive brain imaging. Quetiapine (QTP) and cyclobenzaprine (CBP), as two 5-HT2A receptor antagonists, were successfully labeled with radioactive iodine (125I) using Chloramine-T (CAT) as an oxidizing agent via electrophilic substitution reactions. After studying the parameters affecting the labeling yield, the highest radiochemical yields of125I-QTP and 125I-CBP were found to be $94.5 \% \pm 1.0$ and $91.7 \% \pm 0.6$, respectively, at $\mathrm{pH}$ 2. The biodistribution and the SPECT/CT image showed that the maximum uptake of radioiodinated-QTP by the mouse brain was $10.2 \%$ and $10.9 \%$ at 120 minutes post-injection, while the uptake percentages of radioiodinated-CBP were $7.7 \%$ and $12.4 \%$ at 240 minutes post-injection. The results have shown that radioiodinated-QTP and radioiodinated-CBP are novel radiopharmaceuticals and may be used for brain imaging.
\end{abstract}

\section{INTRODUCTION}

In recent years, the development of new brain imaging radiopharmaceuticals for single-photon computed tomography / computed tomography (SPECT / CT) emission has rapidly progressed. SPECT / CT alone or combination with positron emission tomography (PET) and/or functional magnetic resonance imaging (FMRI) is used for the assessment of human cognition, the monitoring of neuroreceptor structures, the detection or evaluation of neurological disease development and following up responses to psychiatric treatments [1-11]. However, in comparison with PET, SPECT / CT has the advantage of being widely available worldwide. The physical properties of ${ }^{125} \mathrm{I}$ (half-life $\left(t_{1 / 2}\right)=59.4 \mathrm{~d}$ and $\mathrm{E}_{\gamma}$ $=35.5 \mathrm{keV}$ ) allowed it to be used in in-vitro and radiolabeling studies. Due to the similarities between different radioiodine isotopes $\left({ }^{123} \mathrm{I},{ }^{124} \mathrm{I},{ }^{125} \mathrm{I}\right.$ and $\left.{ }^{131} \mathrm{I}\right)$ in their chemical properties, they can be used in the radiolabeling process [12].Because $10 \%$ of its energy is via gamma rays, ${ }^{131} \mathrm{I}$ radionuclide was used for the determination of the radiochemical purity, biodistribution and SPECT imaging[13].
Quetiapinefumarate (2-[2-(4-dibenzo[b,f] [1,4] thiazepine -11-yl-1-piperazinyl)ethoxy]ethanol) is a typical antipsychotic agent used for the treatment of schizophrenia, bipolar disorder and major depressive disorder[14-15].Sometimes, it is also used as a sleep aid due to its sedating effect, but this use is not recommended [16].The antipsychotic activity of quetiapine may be due to a combination of antagonism in the frontal cortex at 5HT2A receptors and D2 receptors in the mesolimbic pathway. 5- $\mathrm{HT}_{2 \mathrm{~A}}$ receptors antagonism relieves negative symptoms of schizophrenia, while antagonism at $\mathrm{D}_{2}$ receptors relieves its positive symptoms.

Cyclobenzaprine hydrochloride (3-(5H-dibenzo[a,d] cyclohepten-5-ylidene)- $N, N$-dimethyl-1-propanamine) is a muscle relaxant used to relieve skeletal muscle spasms and associated pain in acute musculoskeletal conditions [17].CBP does not work directly on the muscle or the neuromuscular junction, but through central action; it relieves muscle spasms, likely at the level of the brain stem. 
CBP binds to the serotonin receptor and is known to be a 5-HT2A receptor antagonist- that improves muscle tone by reducing serotonergic neuronal activity. Both QTP and CBP were reported to have a high penetration probability (about 0.9906 and 0.9512 , respectively) via BBB[18].The chemical structures of QTP and CBP are shown in Fig. (1).

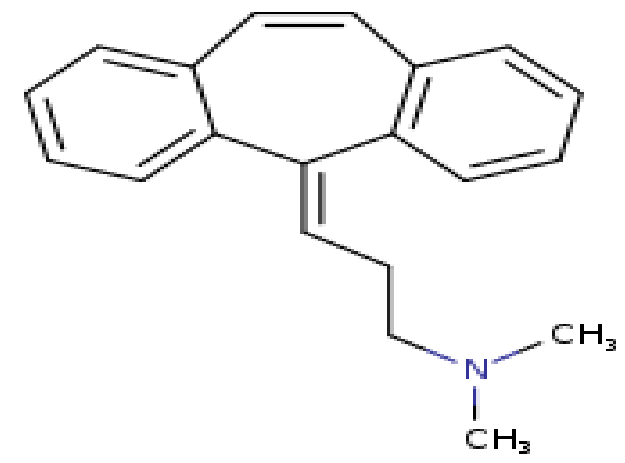

CBP

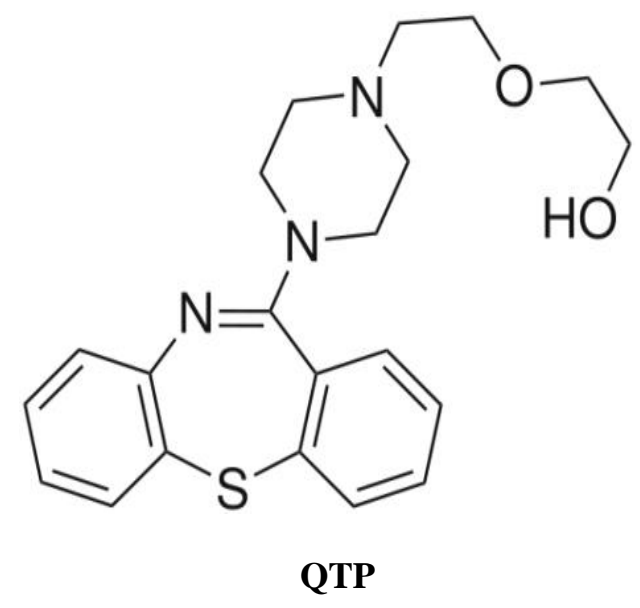

Fig. (1): Chemical structures of CBP and QTP

This study focuses on factors affecting the radioiodination yield of ${ }^{131} \mathrm{I}$-QTP and ${ }^{131} \mathrm{I}$-CBP and the comparison between them as novel radiopharmaceuticals for SPECT / CT brain imaging. In addition, the biodistribution and localization efficacy of the labeled compounds were evaluated in laboratory animals and confirmed using SPECT / CT imaging.

\section{EXPERIMENTAL}

\subsection{Materials}

QTP and CBP were obtained as a gift from the National Organization for Drug Control and Research, Giza, Egypt. CAT was purchased from Aldrish Chemical Company, China. Radioactive iodine-125 ( $\left.\mathrm{Na}^{125} \mathrm{I}\right)$ with
$370 \mathrm{MBq}(10 \mathrm{mCi})$ activity was purchased from Isotope Company, Budapest. Radioactive iodine-131 $\left(\mathrm{Na}^{131} \mathrm{I}\right)$ with $1.85 \mathrm{GBq}(50 \mathrm{mCi})$ activity was presented as a gift from the Radioisotope Production Facility, Egyptian Atomic Energy Authority, Egypt. All chemicals were used in analytical or clinical grades and were used without further purification. Silica gel thin-layer chromatography (SG-TLC) was purchased from Merck, Germany. The Hidex single detector gamma counter was used to measure the radioactivity and SPECT/CT model Syngo, Siemens AG.

\section{METHOD}

\subsection{Radioiodination}

${ }^{125} \mathrm{I}-\mathrm{QTP}$ and ${ }^{125} \mathrm{I}-\mathrm{CBP}$ can be synthesized by direct electrophilic substitution reaction with ${ }^{125} \mathrm{I}$ using CAT as a mild oxidizing agent [19-20]. In brief , an appropriate amount of CAT $(25-250 \mu \mathrm{g})$ dissolved in water was added to the desired amount of QTP or CBP(25-200 $\mu \mathrm{g})$.The $\mathrm{pH}$ of the reaction mixtures $(\mathrm{pH} 2-11)$ was adjusted using different buffer systems. Reactions were allowed to proceed at different time intervals (5-60 min) and at different temperatures (up to $100^{\circ} \mathrm{C}$ ). To quench the reactions, a drop of sodium thiosulfate solution (20 $\mathrm{mg} / \mathrm{mL}$ ) was added to reduce the unreacted iodine to iodide completely.

\subsection{Radiochemical analysis}

Radiochemical yields of ${ }^{125} \mathrm{I}$-QTP and ${ }^{125} \mathrm{I}$-CBP were determined by SG-TLC. The sample was spotted at $2 \mathrm{~cm}$ above the lower edge of the strip $(1.5 \mathrm{~cm}$ wide, 14 $\mathrm{cm}$ long), then TLC was developed with a mixture of chloroform to methanol $(3: 1 \mathrm{v} / \mathrm{v})$. The radiolabeled compounds ( ${ }^{131} \mathrm{I}$-QTP and $\left.{ }^{131} \mathrm{I}-\mathrm{CBP}\right)$ migrated with a solvent front $(\mathrm{Rf}=0.9)$, whereas the free iodide remained near the spotting point at base line ( $\mathrm{Rf}=0-0-1)$. The strip was removed from the developer jar to dry and cut into segments of $1 \mathrm{~cm}$ and its activity was measured using the gamma counter. The radiochemical yield was determined using the following equation [21].

$\%$ Radiochemical yield $=\frac{\text { Activity of labeled copmound }}{\text { Total activity }} \times 100$

\subsection{Radiochemical purity}

The HPLC analysis of ${ }^{131} \mathrm{I}-\mathrm{QTP}$ and ${ }^{131} \mathrm{I}-\mathrm{CBP}$ was performed using $\mathrm{NaI} / \mathrm{Tl}$ crystal gamma counter. Samples $(5-10 \mu \mathrm{L})$ of the reaction mixtures of both ${ }^{131} \mathrm{I}-\mathrm{QTP}$ and ${ }^{131}$ I-CBP were injected in a reversed phase column RP-C18.The elution process was carried out using methanol: acetonitrile: $\mathrm{pH} 6.6$ phosphate buffer 
$(15: 40: 45 \mathrm{v} / \mathrm{v})$ for ${ }^{131} \mathrm{I}-\mathrm{QTP}$ and methanol:0.02 mol/1 $\mathrm{KH}_{2} \mathrm{PO}_{4}(75: 25 \mathrm{v} / \mathrm{v}, \mathrm{pH} 3$ was adjusted using $1 \%$ ophosphoric acid)for ${ }^{131} \mathrm{I}-\mathrm{CBP}$ as mobile phases at $1 \mathrm{~mL} / \mathrm{min}$ flow rate. The fractions were collected and counted using NaI/TI crystal gamma counter [22-23].

\subsection{Lipophilicity}

A partition coefficient experiment was conducted with ${ }^{125}$ I-QTP and ${ }^{125}$ I-CBP for in vitro screening of their ability to pass through the BBB. This experiment was performed by mixing ${ }^{125} \mathrm{I}-\mathrm{QTP}$ or ${ }^{125} \mathrm{I}-\mathrm{CBP}$ with equal volumes of 1-octanol and phosphate buffer $(0.025 \mathrm{~mol} / \mathrm{L}$ at $\mathrm{pH}$ 7.4) in a centrifuge tube. The mixture was vortexed at room temperature for $1 \mathrm{~min}$, then centrifuged at 5,000 rpm for $5 \mathrm{~min}$. Samples $(100 \mu \mathrm{L})$ were pipetted into test tubes and counted for each phase. Measurements were made in triplicate and the values for the partition coefficient were expressed as $\log \mathrm{p}$ [24].

\subsection{In vivo biodistribution study}

Biological research experiments were carried out in accordance with the guidelines laid down by the Egyptian Atomic Energy Authority and approved by the Labeled Compounds Department. Swiss albino male mice weighing between 25-30 $\mathrm{g}$ were selected for biodistribution studies. Three mice were used for each radio-compound at each time point. Mice were injected with ${ }^{131}$ I-QTP or ${ }^{131}$ I-CBP compounds via the caudal (tail) vein. Animals were humanely killed at different time intervals and the blood was collected by cardiac puncture. Subsequently, the brain and other organs were dissected and washed twice with normal saline to remove adhesive tissue/fluid. The radioactivity percentage in each tissue/organ was measured using a gamma scintillation counter.

\subsection{In vivo SPECT/CT imaging}

Mice were anesthetized by intravenous diazepam injection $(5 \mu \mathrm{L} / \mathrm{g})$ and then injected ${ }^{131} \mathrm{I}$-QTP or ${ }^{131} \mathrm{I}-$ $\mathrm{CBP}$ via the caudal vein containing about37 $\mathrm{MBq}$ (1 $\mathrm{mCi}$ ) radioactive iodine-131. Each mouse was positioned at the chosen time intervals (10, 60, 120 and $240 \mathrm{~min}$ ) for imaging. The mice were imaged in prone and feet first position using a pinhole collimator with a configuration of 180 head for $10 \mathrm{~min}$ acquisition duration. The images obtained were a planner with matrix $512 \times 512$ and an optical zoom 3 .

\section{RESULTS AND DISCUSSION}

The structure of ${ }^{125} \mathrm{I}-\mathrm{CBP}$ and ${ }^{125} \mathrm{I}-\mathrm{QTP}$ via reaction of CBP and QTP with iodine-125 in the presence of $\mathrm{CAT}$ at $\mathrm{pH}=2$ is shown in Eq. (2) and (3) respectively. Preparation and confirmation structure of the iodo-CBP and iodo-QTP were investigated using stable iodine for the preparation of large amounts to enable their separations for characterization, and prepared under the same conditions as those used for the preparation of ${ }^{125} \mathrm{I}-$ CBP and ${ }^{125}$ I-QTPThe iodo-CBP and iodo-QTP were characterized by proton NMR.

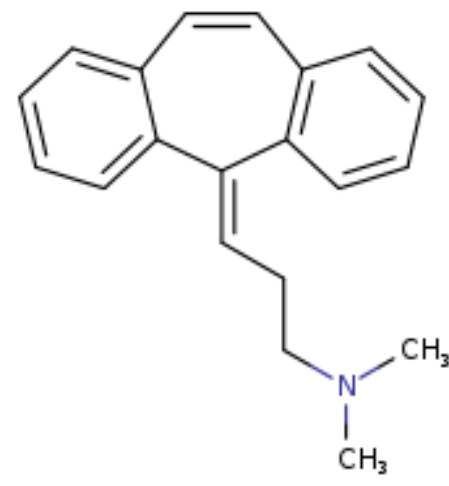

CBP

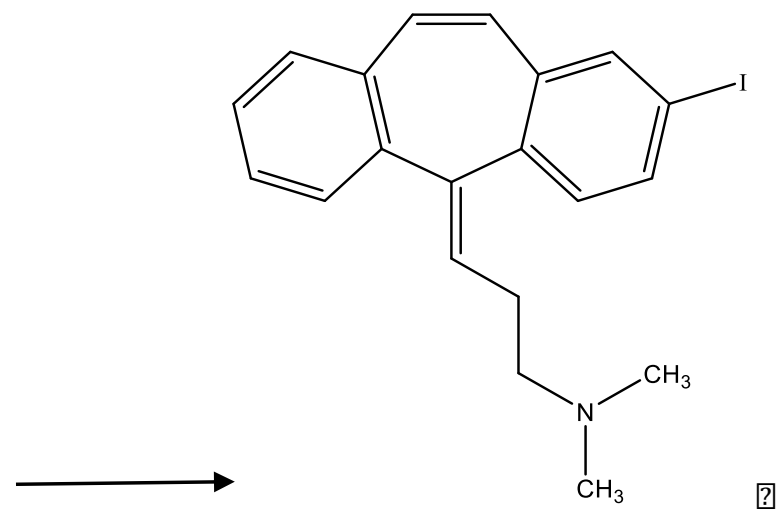

${ }^{125} \mathrm{I}-\mathrm{CBP}$

The ${ }^{1}$ HNMR spectrum of iodo- CBP in (Acetone-d6) revealed signals at:

2.0-2.4(t.q-4H-2methylene aliphatic) 2.9-2.9(s.s-6H-2 methyl) 5.9(t.1H methane $-\mathrm{C}=\mathrm{C}-\mathrm{H}$ aliphatic) 6.9-6.9(d.d2H H$\mathrm{C}=\mathrm{C}-\mathrm{H}$ aliphatic) $7.2-7.3$ (m.4H benzene) $7.5-7.7$ (m.3H-benzene). 


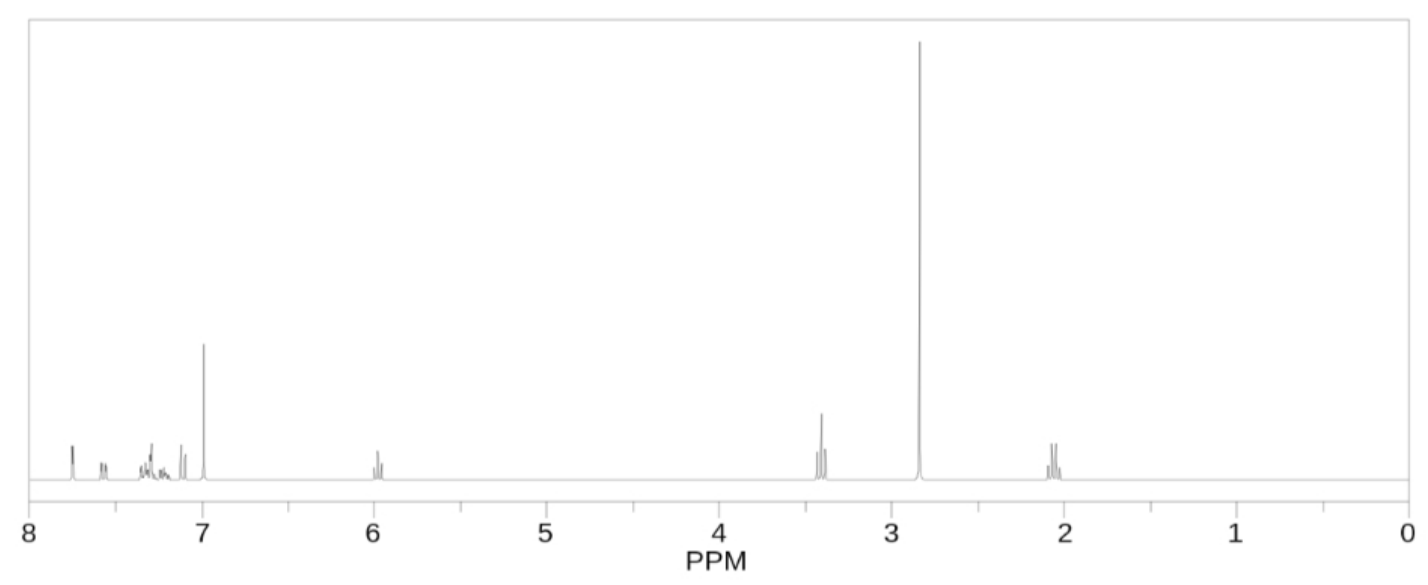

Fig. (2): HNMR spectrum of iodo-CBP
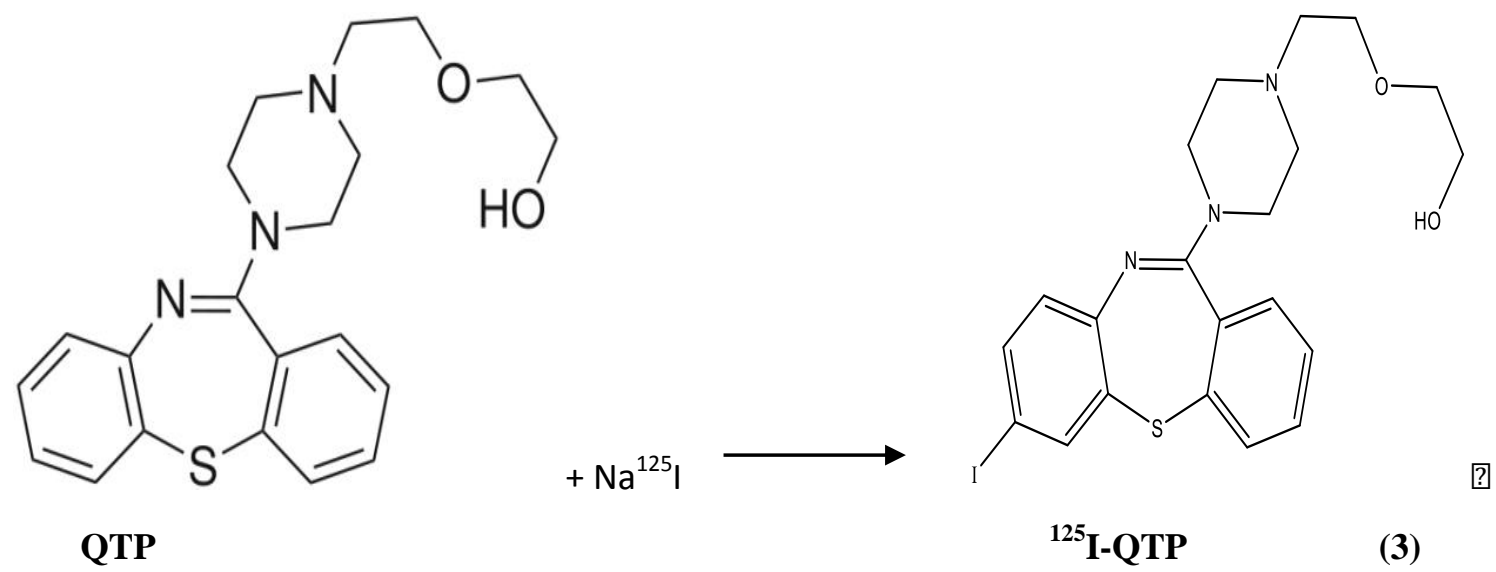

The ${ }^{1}$ HNMR spectrum of iodo- QTP in (DMSO-d6) revealed signals at: 2.2-2.2(t.t-4H.2 methylene aliphatic) 2.3-2.6(t.t-4H2 methylene aliphatic) $2.8-2.9$ (t.t- $4 \mathrm{H}-2$ methylene cyclic) $2.8-2.9(4 \mathrm{H}-2$ methylene cyclic aliphatic) $5.6(1 \mathrm{H}-\mathrm{OH}$ alcohol) $6.1-$ 7.2(m-3H-benzene) $7.2-7.6(\mathrm{~m}-4 \mathrm{H}-$ benzene).

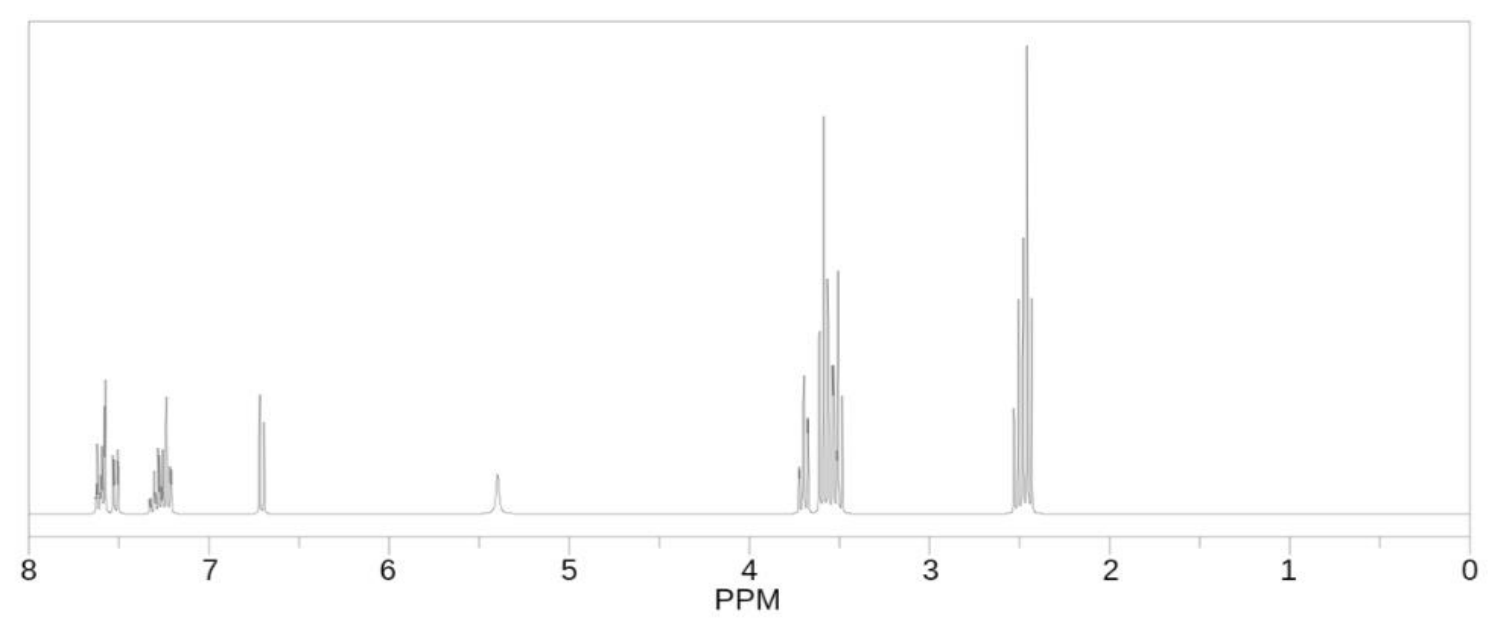

Fig. (3): HNMR spectrum of iodo-QTP 


\subsection{Optimization of the radiolabeling process}

\subsubsection{Effect of substrate amount}

The radiochemical yield depends on the quantity of ${ }^{125} \mathrm{I}$-QTP or ${ }^{125} \mathrm{I}$-CBP as shown in Fig. (4), where reactions were performed at different substrate quantities (25-200 $\mu \mathrm{g})$ while the other parameters (CAT, pH reaction, reaction time and temperature) remained constant. Radiolabeling yields of ${ }^{125} \mathrm{I}$-QTP and ${ }^{125} \mathrm{I}-\mathrm{CBP}$ were at a maximum of $100 \mu \mathrm{g}$ of substrate, which may be attributed to the fact that this substrate quantity is sufficient to capture the entire iodonium ion produced [21].By increasing the amount of substrate above the optimum value, the yields for radiolabeling were reduced because the molarity of both of CBP and QTP exceeded the molarity of iodonium ions presented in the solution [25].

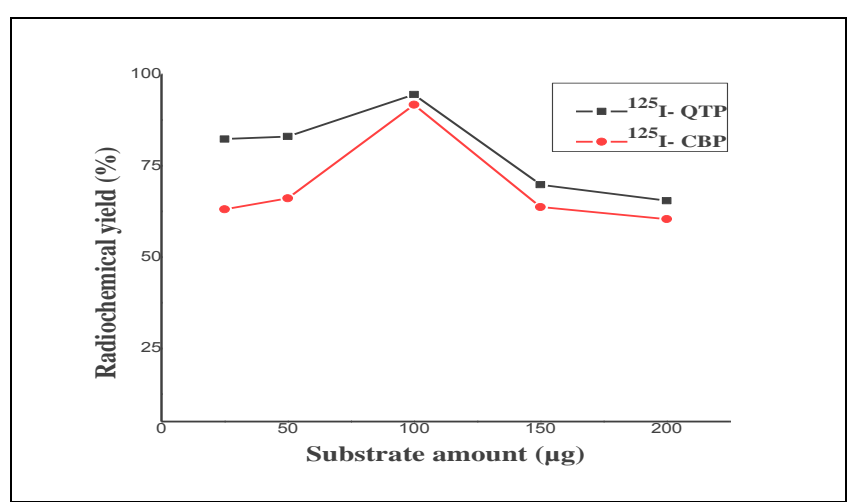

Fig. (4): Radiochemical yieldsof ${ }^{125} I-Q T P$ and ${ }^{125} I-C B P$ as a function of substrate amount

\subsubsection{Effect of CAT amount}

The effect of the amount of oxidizing agent on the radiochemical yields of ${ }^{125}$ I-QTPand ${ }^{125} \mathrm{I}$-CBP is shown in Fig. (5).The radiochemical yield of ${ }^{125} \mathrm{I}$-CBP increased to $91.7 \%$ at a CAT amount of $150 \mu \mathrm{g}$, whereas the ${ }^{125} \mathrm{I}$-QTP yield reached a maximum of $94.5 \%$ at a CAT amount of $50 \mu \mathrm{g}$. A further increase in the amount of CAT led to a decrease in the radiochemical yields and this may be due to the formation of undesirable by-products resulted from oxidative side reactions $[12,21]$.

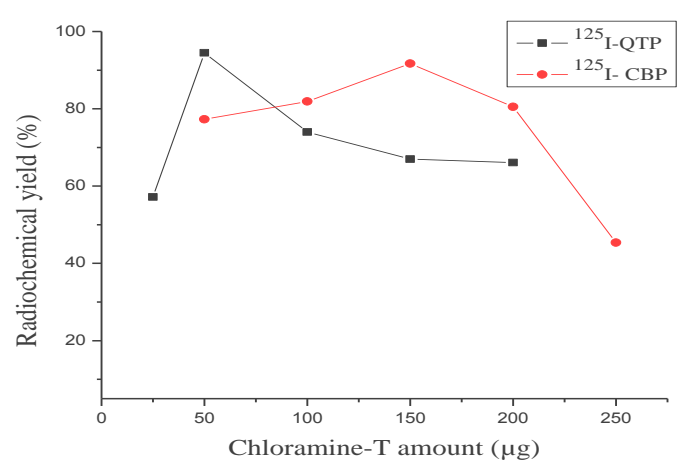

Fig. (5): Radiochemical yields of 125I-QTP and 125I-CBP as a function of CAT amount

\subsubsection{Effect of temperature}

The binding of iodonium ion to the molecule of substrate is energy-dependent. As shown in Fig. (6), the maximum radiochemical yields of ${ }^{125} \mathrm{I}-\mathrm{QTP}$ and ${ }^{125} \mathrm{I}-$ CBP were obtained at $60^{\circ} \mathrm{C}$ and $70^{\circ} \mathrm{C}$, respectively, and radiochemical yields decreased gradually as temperatures increased to $100^{\circ} \mathrm{C}$, probably due to the thermal decomposition of radiolabeled compound

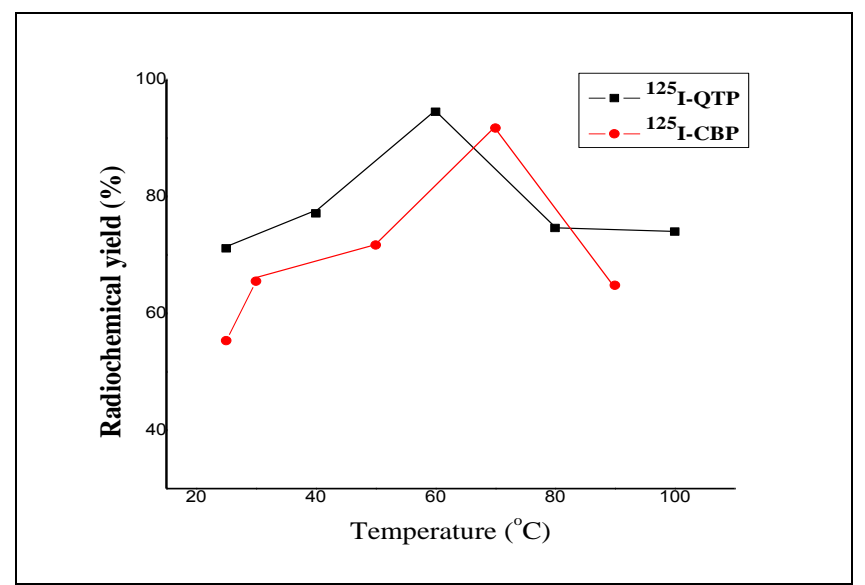

Fig. (6): Radiochemical yields of 125I-QTP and 125I-CBP as a function of reaction temperature

\subsubsection{Effect of $\mathbf{p H}$ of reaction medium}

The oxidizing CAT species are dependent on the $\mathrm{pH}$ of the medium and the condition of the reaction [26].The $\mathrm{pH}$ of the reaction medium was studied at a $\mathrm{pH}$ range from 2 to 11, as shown in Fig. (7). At $\mathrm{pH} 2$, the yields of ${ }^{125} \mathrm{I}$-QTP and ${ }^{125} \mathrm{I}$-CBP exceeded the maximum (94.5\% and $91.7 \%$, respectively) due to an increase in benzene ring protonation. When the $\mathrm{pH}$ of the reaction mixtures shifted to the alkaline medium, the yield dropped sharply to $30.4 \%$ and $41.9 \%$ at $\mathrm{pH} 11$ for ${ }^{125} \mathrm{I}$ QTP and 125I-CBP, respectively, due to the formation of hypoiodite ion $\left(\mathrm{IO}^{-}\right)$and iodate $\left(\mathrm{IO}_{3}{ }^{-}\right)$which are not suitable for iodinated process $[27,28]$.

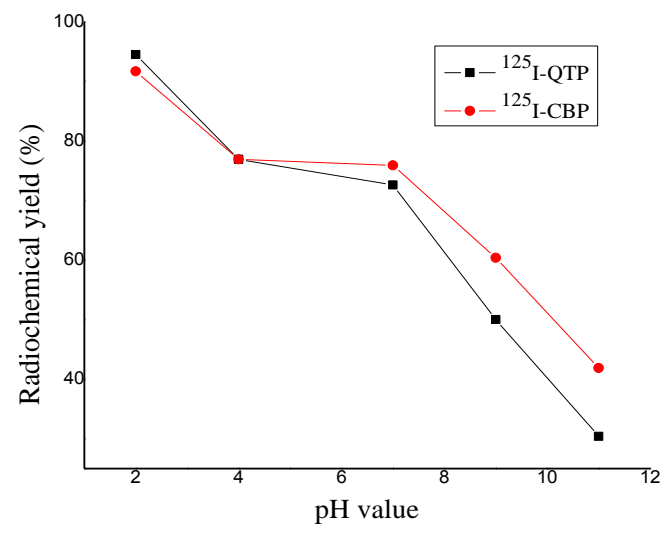

Fig. (7): Radiochemical yields of ${ }^{125}$ I-QTP and ${ }^{125}$ I-CBP as a function of $\mathrm{pH}$

Arab J. Nucl. Sci. Appl., Vol. 54, 2, (2021) 


\subsubsection{Effect of reaction time}

The radiochemical yields of ${ }^{125} \mathrm{I}-\mathrm{QTP}$ and ${ }^{125} \mathrm{I}$ CBP were determined at different time intervals ranging from 5 to $60 \mathrm{~min}$, as shown in Fig. (8). The radiolabeling yield of ${ }^{125} \mathrm{I}$-QTP increased to $94.5 \%$ in 30 min. It appears that short reaction time is not sufficient for CAT to fully react with iodide ions and to generate iodonium ions. It is also evident from the Figure that the radiochemical yield of ${ }^{125} \mathrm{I}$-CBPis substantially increased to maximum $(93.4 \%)$ at $45 \mathrm{~min}$, but this is considered time consuming, because 30 min produces a very good yield on labeling $(91.7 \%)$.

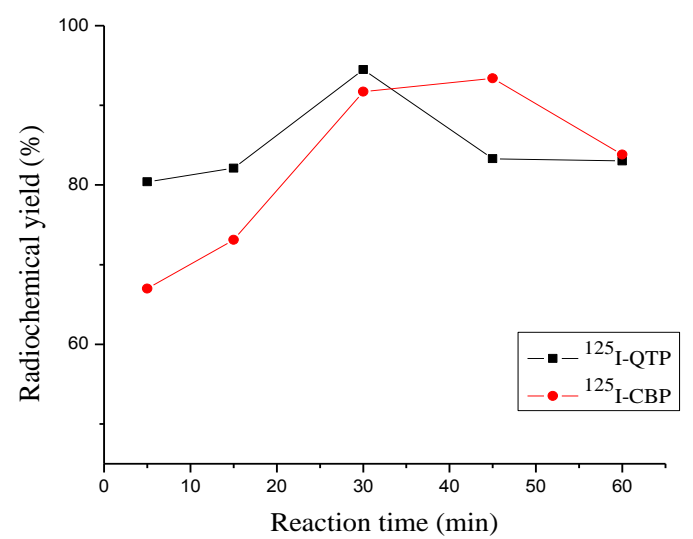

Fig. (8): The radiochemical yields of125I-QTP and 125I-CBP as reaction time function

\subsection{In vitro stability}

The in vitro stability of ${ }^{125} \mathrm{I}-\mathrm{QTP}$ and ${ }^{125} \mathrm{I}-\mathrm{CBP}$ was studied in order to evaluate the time that they could be safely injected. It was determined along $24 \mathrm{~h}$ and the data are listed in Table (1). The data clearly confirmed that the ${ }^{125}$ I-QTP tracer was stable for $4 \mathrm{~h}$ without a sufficient identification of by-products in the reaction mixture. The stability results also showed that ${ }^{125} \mathrm{I}-\mathrm{CBP}$ was stable up to $4 \mathrm{~h}$ with a radiochemical yield of $89.0 \%$.

Table (1): In vitro stability of the prepared ${ }^{125} \mathrm{I}-\mathrm{QTP}$ and ${ }^{125} \mathrm{I}-$ CBP under optimum labeling conditions

\begin{tabular}{ccc}
\hline $\begin{array}{c}\text { Time post labeling } \\
(\mathrm{h})\end{array}$ & $\begin{array}{c}125 \\
\text { I-QTP labeling } \\
\text { yield (\%) }\end{array}$ & $\begin{array}{c}{ }^{125} \text { I-CBP labeling } \\
\text { yield (\%) }\end{array}$ \\
\hline 1 & $93.4 \pm 1.1$ & $90.1 \pm 1.3$ \\
2 & $92.3 \pm 1.0$ & $89.7 \pm 1.7$ \\
4 & $91.0 \pm 0.5$ & $89.0 \pm 1.4$ \\
8 & $87.8 \pm 2.1$ & $80.1 \pm 1.9$ \\
24 & $86.9 \pm 2.7$ & $77.6 \pm 2.7$ \\
\hline
\end{tabular}

\subsection{Lipophilicity}

The partition coefficient values of ${ }^{125} \mathrm{I}-\mathrm{QTP}$ and ${ }^{125} \mathrm{I}$-CBP were $1.97 \pm 0.01$ and $1.76 \pm 0.03$, respectively, indicated that ${ }^{125} \mathrm{I}$-QTP and ${ }^{125} \mathrm{I}-\mathrm{CBP}$ are very lipophilic and can easily cross the BBB.

\subsection{HPLC analysis}

The HPLC analysis showed that the retention times for iodide and ${ }^{131} \mathrm{I}$-QTP (Rt) were 3 and $9 \mathrm{~min}$, respectively, as shown in Fig. 9. In the case of CBP, as shown in Figure (10), the Rt of iodide and 131I-CBP were found to be 5 and 9 min respectively. The eluated fractions of ${ }^{131}$ I-QTP and ${ }^{131}$ I-CBP that contain the labeled compounds were collected individually. Those pooled fractions were evaporated into dryness. The traces were then dissolved in the physiological saline and sterilized using a filter of $0.22-\mu \mathrm{m}$ Millipore. The ${ }^{131}$ I-QTP and ${ }^{131}$ I-CBP were then appropriate for biodistribution and imaging.

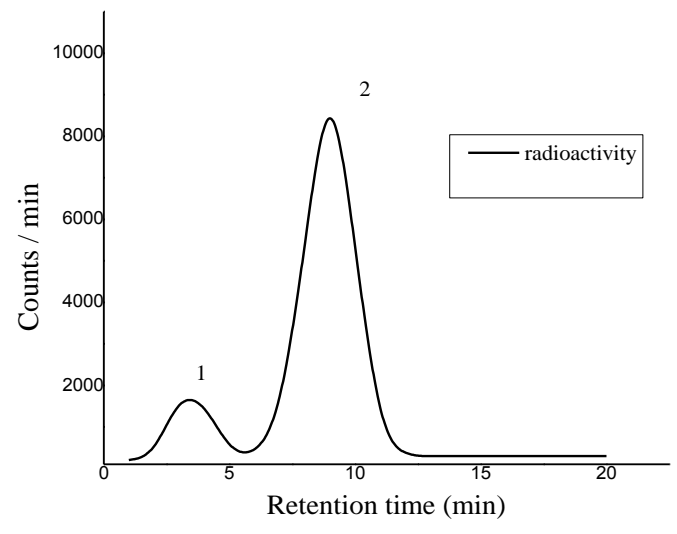

Fig. (9): HPLC elution profile of QTP, Peaks: (1) free 131I and (2) 131I-QTP

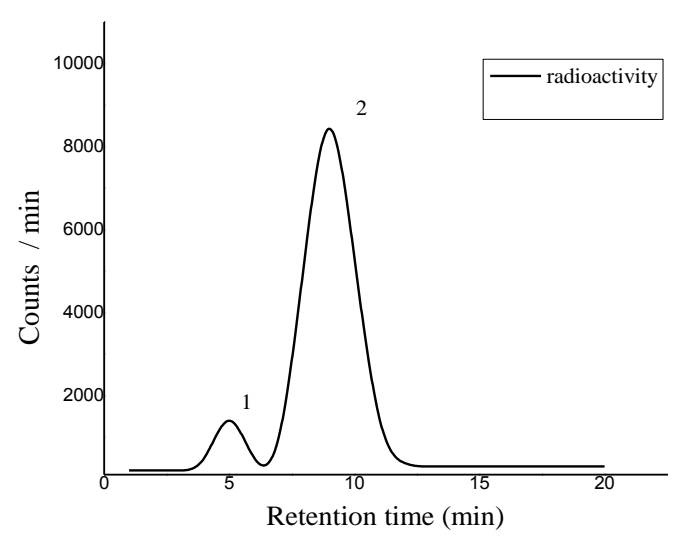

Fig. (10): HPLC elution profile of CBP, Peaks: (1) free 131I and (2)131I-CBP 


\subsection{In vivo biodistribution study}

Table (2) shows the biodistribution pattern of ${ }^{131} \mathrm{I}-$ QTP and ${ }^{131} \mathrm{I}$-CBP in normal albino mice. Because the elimination of QTP is mainly due to hepatic metabolism [29], the tracer passes to the small intestine through the liver, which holds an early uptake of the tracer reaching $5.8 \%$ at $10 \mathrm{~min}$ and increased to $10.7 \%$ at $120 \mathrm{~min}$ post injection. The data also showed that ${ }^{131} \mathrm{I}$-QTP remained in the intestine at $7.8 \%$ after $10 \mathrm{~min}$ and increased to $22.3 \%$ after 240 min from the injection. Because CPB is excreted by the kidney [30], ${ }^{131}$ I-CBP removed from circulation primarily via urine is approximately $28.9 \%$ at $240 \mathrm{~min}$ after injection of the tracer. The low activity in the thyroid gland is representative ${ }^{131} \mathrm{I}-\mathrm{QTP}$ and ${ }^{131} \mathrm{I}$ CBP is stable in vivo against biological decomposition.

With respect to brain radioactivity and that in the blood per gram of tissue(target to non-target), the ratio is concluded to have increased over time and reached its maximum value of 1.2 and 1.9 at $120 \mathrm{~min}$ and $240 \mathrm{~min}$ post injection for ${ }^{131} \mathrm{I}$-QTP and ${ }^{131} \mathrm{I}$-CBP, respectively. This was due to high bloodstream clearance of the tracer, although low brain tissue washes-out.

Table (2): Biodistribution pattern of ${ }^{131}$ I-QTP and ${ }^{131}$ I-CBP in normal mice at different times post injection

\begin{tabular}{|c|c|c|c|c|c|c|c|c|}
\hline \multirow{3}{*}{ Organ or body fluid } & \multicolumn{8}{|c|}{$\%$ Injected dose/organ at different time intervals (min) } \\
\hline & \multicolumn{4}{|c|}{${ }^{125} \mathrm{I}-\mathrm{QTP}$} & \multicolumn{4}{|c|}{${ }^{125} \mathrm{I}-\mathrm{CBP}$} \\
\hline & $10 \mathrm{~min}$ & $60 \mathrm{~min}$ & $120 \mathrm{~min}$ & $240 \mathrm{~min}$ & $10 \mathrm{~min}$ & $60 \mathrm{~min}$ & $120 \mathrm{~min}$ & $240 \mathrm{~min}$ \\
\hline Brain & $0.5 \pm 0.1$ & $2.3 \pm 0.1$ & $3.5 \pm 0.3$ & $2.7 \pm 0.3$ & $0.4 \pm 0.1$ & $2.0 \pm 0.1$ & $2.3 \pm 0.2$ & $2.9 \pm 0.1$ \\
\hline Blood & $21.1 \pm 1.2$ & $16.6 \pm 0.5$ & $10.6 \pm 0.2$ & $9.4 \pm 0.2$ & $6.6 \pm 0.3$ & $11.7 \pm 0.2$ & $8.9 \pm 0.3$ & $5.4 \pm 0.2$ \\
\hline Liver & $5.8 \pm 0.2$ & $8.6 \pm 0.3$ & $10.7 \pm 0.2$ & $9.1 \pm 0.2$ & $4.0 \pm 0.3$ & $6.1 \pm 0.4$ & $6.3 \pm 0.2$ & $3.5 \pm 0.2$ \\
\hline Intestine & $7.8 \pm 0.4$ & $14.4 \pm 0.5$ & $19.6 \pm 0.9$ & $22.3 \pm 1.7$ & $6.2 \pm 0.1$ & $6.6 \pm 0.4$ & $11.8 \pm 0.5$ & $10.5 \pm 0.3$ \\
\hline Stomach & $4.8 \pm 0.1$ & $7.3 \pm 0.4$ & $15.0 \pm 0.5$ & $16.1 \pm 0.6$ & $5.9 \pm 0.2$ & $9.1 \pm 0.5$ & $11.7 \pm 0.2$ & $21.0 \pm 1.6$ \\
\hline Lungs & $1.3 \pm 0.1$ & $1.3 \pm 0.2$ & $0.9 \pm 0.1$ & $0.9 \pm 0.1$ & $0.9 \pm 0.1$ & $0.8 \pm 0.2$ & $0.6 \pm 0.1$ & $0.6 \pm 0.1$ \\
\hline Heart & $1.0 \pm 0.1$ & $0.9 \pm 0.1$ & $0.6 \pm 0.1$ & $0.5 \pm 0.1$ & $0.6 \pm 0.1$ & $0.6 \pm 0.1$ & $0.3 \pm 0.1$ & $0.2 \pm 0.1$ \\
\hline Kidneys & $6.8 \pm 0.2$ & $2.9 \pm 0.4$ & $2.8 \pm 0.3$ & $2.7 \pm 0.1$ & $12.5 \pm 0.2$ & $12.5 \pm 0.1$ & $12.3 \pm 0.3$ & $11.1 \pm 0.1$ \\
\hline Spleen & $0.9 \pm 0.1$ & $0.9 \pm 0.1$ & $1.0 \pm 0.1$ & $1.0 \pm 0.1$ & $0.4 \pm 0.1$ & $0.5 \pm 0.1$ & $0.3 \pm 0.1$ & $0.3 \pm 0.1$ \\
\hline Muscles & $41.8 \pm 0.3$ & $12.1 \pm 0.4$ & $12.3 \pm 0.3$ & $11.4 \pm 0.5$ & $31.7 \pm 1.3$ & $14.4 \pm 2.2$ & $3.5 \pm 0.9$ & $2.8 \pm 0.5$ \\
\hline Bones & $2.4 \pm 0.2$ & $15.5 \pm 0.3$ & $2.5 \pm 0.1$ & $1.6 \pm 0.1$ & $19.4 \pm 0.4$ & $24.2 \pm 0.4$ & $16.8 \pm 0.1$ & $12.6 \pm 0.1$ \\
\hline Thyroid & $0.4 \pm 0.2$ & $0.2 \pm 0.1$ & $0.2 \pm 0.1$ & $0.2 \pm 0.1$ & $0.2 \pm 0.1$ & $0.4 \pm 0.2$ & $0.2 \pm 0.1$ & $0.2 \pm 0.1$ \\
\hline Urine & $5.3 \pm 0.2$ & $17.0 \pm 0.3$ & $20.1 \pm 0.1$ & $22.2 \pm 2.4$ & $11.1 \pm 0.1$ & $11.2 \pm 0.1$ & $25.2 \pm 0.5$ & $28.9 \pm 0.6$ \\
\hline Brain* & $1.4 \pm 0.1$ & $7.3 \pm 0.1$ & $10.2 \pm 0.3$ & $6.7 \pm 0.3$ & $1.0 \pm 0.1$ & $4.9 \pm 0.1$ & $5.7 \pm 0.2$ & $7.7 \pm 0.2$ \\
\hline Blood* & $11.8 \pm 1.2$ & $12.1 \pm 0.5$ & $8.7 \pm 0.2$ & $7.7 \pm 0.2$ & $3.8 \pm 0.2$ & $7.5 \pm 0.2$ & $6.0 \pm 0.1$ & $4.0 \pm 0.2$ \\
\hline$(\mathrm{Br} / \mathrm{Bl})^{*}$ & 0.1 & 0.6 & 1.2 & 0.9 & 0.3 & 0.7 & 1.0 & 1.9 \\
\hline
\end{tabular}

*\% Injected dose / g tissue; Br: Brain; Bl: Blood 

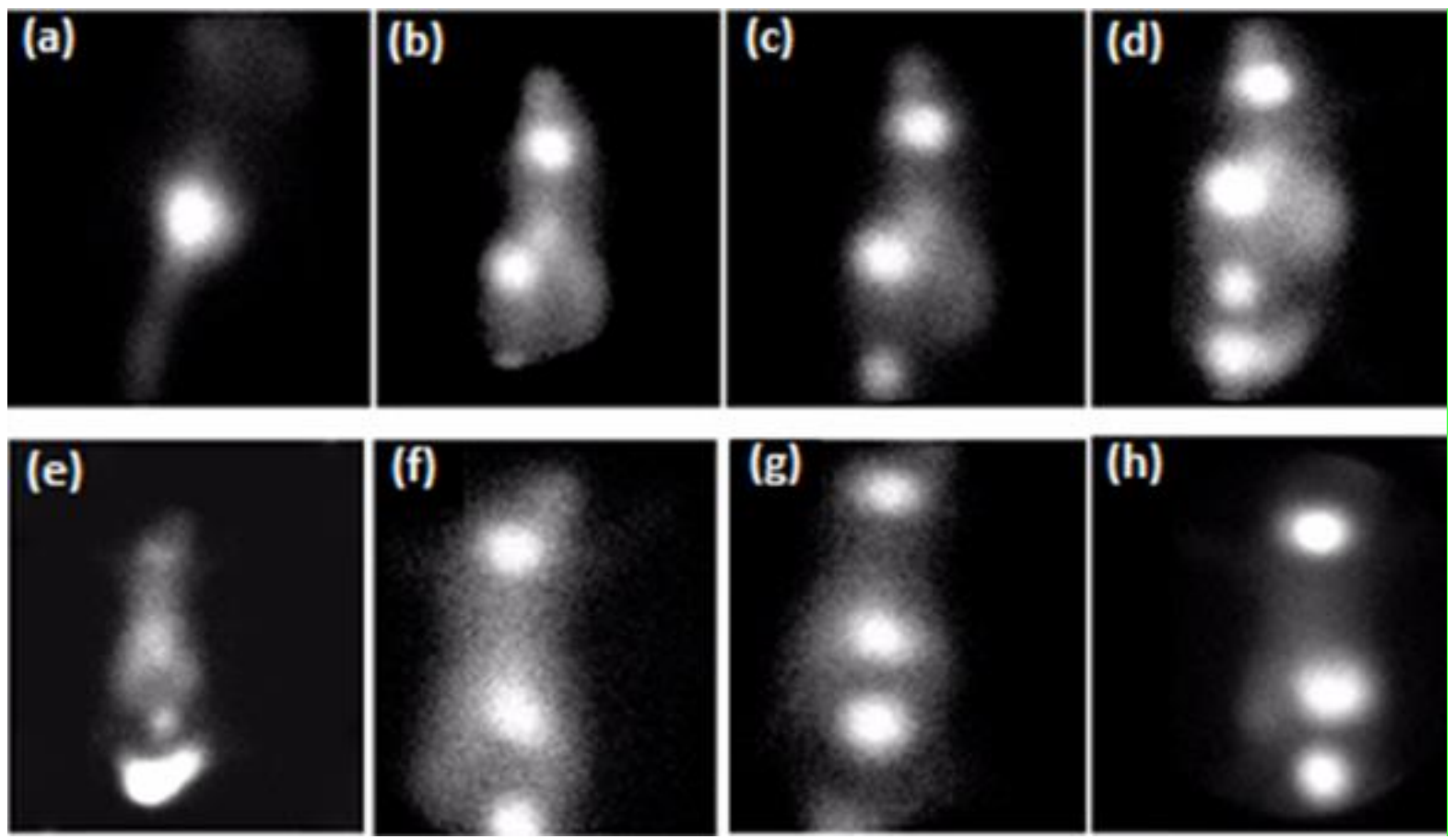

Fig. (11): Pinhole SPECT/CT brain scans of two mice injected with131I-QTP (a-d) and 131I-CBP (e-h) at several periods of time $(10,60,120$ and $240 \mathrm{~min}$ from left to right)

Table (3): The percentage of doses injected of 131I-QTP in some organs as per SPECT/CT imaging

\begin{tabular}{c|c|c|c|c}
\hline \multirow{2}{*}{ Organs } & \multicolumn{4}{|c}{ Time post injection (min) } \\
\cline { 2 - 5 } & $\mathbf{1 0}$ & $\mathbf{6 0}$ & $\mathbf{1 2 0}$ & $\mathbf{2 4 0}$ \\
\hline Brain & $0.4 \%$ & $9.2 \%$ & $10.9 \%$ & $10.7 \%$ \\
Liver & $1.5 \%$ & $7.6 \%$ & $10.9 \%$ & $13.4 \%$ \\
Bladder & $1.2 \%$ & $1.5 \%$ & $4.2 \%$ & $5.4 \%$ \\
\hline
\end{tabular}

Table (4): The percentage of doses injected of 131I-CBP in certain organs as per SPECT/CT imaging

\begin{tabular}{c|c|c|c|c}
\hline \multirow{2}{*}{ Organs } & \multicolumn{4}{|c}{ Time post injection (min) } \\
\cline { 2 - 5 } & $\mathbf{1 0}$ & $\mathbf{6 0}$ & $\mathbf{1 2 0}$ & $\mathbf{2 4 0}$ \\
\hline Brain & $3.5 \%$ & $8.1 \%$ & $10.3 \%$ & $12.4 \%$ \\
Liver or GIT & $7.2 \%$ & $10.2 \%$ & $16.0 \%$ & $12.3 \%$ \\
Bladder & $3.6 \%$ & $6.1 \%$ & $11.9 \%$ & $7.6 \%$ \\
\hline
\end{tabular}

\subsection{SPECT/CT imaging}

Pinhole SPECT/CT brain scans of two mice, one of them injected with ${ }^{131} \mathrm{I}-\mathrm{QTP}$ and the other one injected with ${ }^{131} \mathrm{I}$-CBP are shown in Fig.(11) To explore where each drug is located in the brain at several intervals of time $(10,60,120$ and $240 \mathrm{~min}$ post intravenous injection), the images were taken. In the case of QTP, there was no significant $131 \mathrm{I}-\mathrm{QTP}$ percentage reaching the brain after 10 min of injection $(0.4 \%)$, but after 120 min of injection, it increased to its maximum value (10.9 $\%$ ) as shown in Table (3). Table (4) shows that about 3.5 $\%$ of ${ }^{131}$ I-CBP dose reached the brain after $10 \mathrm{~min}$ of injection and increased gradually with time till reaching $12.4 \%$ after $240 \mathrm{~min}$ of injection. The scintigraphy images were consistent with the findings of the biodistribution studies. 


\section{CONCLUSION}

Radiolabeling of both QTP and CBP were conducted through an electrophilic substitution reaction with high radiolabeling yields of $94.5 \pm 1.0 \%$ and $91.7 \pm 0.6 \%$, respectively. The in vivo biodistribution results showed a higher brain uptake of ${ }^{125}$ I-QTP $(10.2 \pm$ $0.3 \%)$ than that of ${ }^{125} \mathrm{I}-\mathrm{CBP}(7.7 \pm 0.2 \%)$ after 120 and $240 \mathrm{~min}$, respectively, post injection. This uptake was greater than ${ }^{125}$ I-sibutramine and ${ }^{125}$ I-fluoxetine $(5.7 \pm$ 0.19 and $6.14 \pm 0.26 \%$, respectively) [26]. Also, the uptake results in this study were higher than those of the commercially available agents namely, ${ }^{99 \mathrm{~m}} \mathrm{Tc}-\mathrm{ECD}$ and ${ }^{99 \mathrm{~m}} \mathrm{Tc}-\mathrm{HMPAO}$ (4.7 and $2.25 \%$, respectively) [31, 32].These results were confirmed by SPECT/CT brain scans, where the maximum uptake percentages for ${ }^{131} \mathrm{I}$ QTP and ${ }^{131}$ I-CBP were $10.9 \%$ and $12.4 \%$ after 120 and $240 \mathrm{~min}$ post injection respectively. Thus, radioiodinated QTP and CBP are prospective novel radiopharmaceuticals for brain imaging.

\section{REFERENCES}

[1] DevousM.D.Sr. (2002) "Functional brain imaging in the dementias: Role in early detection, differential diagnosis and longitudinal studies", Eur. J. Nucl. Med. Mol. Imaging, 29 (12), 1685.

[2] Catafau A.M. (2001) "Brain SPECT in clinical practice. Part I: perfusion", J. Nucl. Med., 42 (2), 259.

[3] Mazziotta J.C. and Toga A.W. (2002) "Brain mapping: The methods", $2^{\text {nd }}$ Ed., Academic Press, San Diego, USA, 513.

[4] [4] Lee B. and Newberg A. (2005) "Neuroimaging in traumatic brain imaging", NeuroRx, 2 (2), 372.

[5] Bonte F.J., DevousM.D.Sr., In: Sandler M.P., Coleman R.E., Patton J.A., Wackers F.J.T.H. and Gottschalk A., (2003) "Diagnostic nuclear medicine", $4^{\text {th }}$ Ed., Lippincott Williams and Wilkins, Philadelphia, USA, 757.

[6] DevousM.D.Sr., Edited by: Murray I.P.C. and Ell P.J., (1998) "SPECT brain imaging in cerebrovascular disease: Innuclear medicine, in clinical diagnosis and treatment", McGraw-Hill, New York, USA, 631.

[7] Brooks D.J. (2005) "Positron emission tomography and single-photon emission computed tomography in central nervous system drug development", NeuroRx, 2 (2), 226.

[8] Eckert T. andEidelberg D. (2005) "Neuroimaging and therapeutics in movement disorders", NeuroRx, 2 (2), 361.

[9] Heinz A., Jones D.W., Raedler T., Coppola R., Knable M.B. and Weinberger D.R., (2000)
"Neuropharmacological studies with SPECT in neuropsychiatric disorders", Nucl. Med. Biol., 27 (7), 677.

[10] Dickerson B.C. and Sperling R.A., (2005) "Neuroimaging biomarkers for clinical trials of disease-modifying therapies in Alzheimer's disease", NeuroRx, 2 (2), 348.

[11] Bammer R., Skare S., Newbould R., Liu C., Thijs V., Ropele S., Clayton D. B., Krueger G., Moseley M.E. and Glover G.H., (2005) "Foundations of advanced magnetic resonance imaging", NeuroRx, 2 (2), 167.

[12] Nourihan.S.Farrag, Hanan.A.El-Sabagh, Abdulaziz M.Al-mahallawi, Abeer.M.Amin\&Ahmed. AbdElBary, WaelMamdouh, (2017) "Comparative Study on Radiolabeling and Biodistribution of Core-Shell Silver/Polymeric Nanoparticles-Based Theranostic for Tumor Targeting" International journal of pharmaceutics, 529,123:133.

[13] Tamer M.Sakr, O.M.Khowessah, M.A.Motaleb, A.AbdEl-Bary, M.T. El-Kolaly, Mohamed M. Swidan, (2018)'I- 131 doping of silvernanoparticles platform for tumortheranosis guided drug delivery"European Journal of Pharmaceutical Sciences , 122,239:245.

[14] Riedel M., Müller N., Strassnig M., Spellmann I., Severus E. and Hans-Jürgen Möller H-J., (2007) "Quetiapine in the treatment of schizophrenia and related disorders", Neuropsychiatr. Dis. Treat., 3 (2), 219.

[15] Komossa K., Depping A.M., Gaudchau A., Kissling W. andLeucht S., (2010)"Second-generation antipsychotics for major depressive disorder and dysthymia",Cochrane Database Syst. Rev., 12.

[16] Gugger J.J. andCassagnol M., (2010) "Low-dose quetiapine is not a benign sedative-hypnotic agent",Am. J. Addiction., 17(5), $454 x$

[17] Toth P.P. andUrtis J., (2004) "Commonly used muscle relaxant therapies for acute low back pain: A review of carisoprodol, cyclobenzaprine hydrochloride and metaxalone", Clin. Ther., 26 (9), 1355.

[18] Shen J., Cheng F., Xu Y., Li W. and Tang Y., (2010) "Estimation of ADME Properties with substructure pattern recognition", J. Chem. Inf. Model., 50 (6), 1034.

[19] Al-Dayel O.A.F., Al-Suhybani A.A. and El-Garhy M.; "Chloramine-T as Labelling Agent for Oleic Acid and Olive Oil", Isotopenpraxis, 25, 489 (1989).

[20] Bolton, A.E., (1977)"Radioiodination techniques", Radiochemical Center,Amersham, England, 18. 
[21] A.M. Amin,S. E. Soliman, and H. A. El-Aziz, (2010) "Preparationandbiodistribution of $\left[{ }^{125} \mathrm{I}\right]$ Melphalan: a potential radioligandfor diagnostic and therapeutic applications"Journal of labelled compounds and radiopharmaceuticals.,53(1)1:5.

[22] Rosa P.C.P., Pires I.F.R., Markman B.E.O. andPerazzo F.F., (2013) "Development and validation of RP-HPLC method for the determination of related compounds in quetiapinehemifumarate raw material and tablets", J. Appl. Pharm. Sci., 3 (8), 6.

[23] Patel R.D., Chhalotiya U.K., Mehta F.A., Shah D.A. and Bhatt K.K., (2014) "Liquid chromatographic estimation of cyclobenzaprine hydrochloride and aceclofenac in pharmaceutical formulation", Res. Rev. J. Pharm. Pharm. Sci., 3 (3), 37.

[24] A. M. Amin, S. E. Soliman, H. A. El-Aziz and S. A. Abo El-Enein ;(2014)" Radioiodination of Zaleplon and Its in-vivo Biologic Behavior in Mice: An Imaging Probe for Brain "International Journal of Chemistry; 6(1).

[25] A. M. Amin, S. A. Kandil, M. E. Abdel-Hameed, M. E. Aboselim and H. A. El-Ghamry.,(2015)" Purification and biological evaluation of radioiodinated clozapine as possible brain imaging agent", Journal of Radioanalytical and Nuclear Chemistry., 304; 837-844.

[26] Puttaswamy andVaz N., (2001) "Kinetics of oxidation of acidic amino acids by sodium $N$ bromo-benzenesulphonamide in acid medium: A mechanistic approach", P. Indian AS-Chem. Sci., 113 (4), 325.

[27] M. A. Motaleb, M. T. El-Kolaly, H. M. Rashed, A. AbdEl-Bary, (2011) "Novelradioiodinatedsibutramine and fluoxetine as models for brain imaging" $\mathrm{J}$. RadioanalNuclChem, 289:915-921.

[28] S. I. Khater, Dina M. El-Sharawy, Marwa S. El Refaye, Nourihan S. Farrag, (2020) “Optimization and tissue distribution of [125I] iododomperidone as a radiotracer for D2-receptor imaging" Journal of Radioanalytical and Nuclear Chemistry, 325:343-355.

[29] E. Prieto, J. A. Micó, J. J. Meana and S. Majadas, (2010) " Neurobiological bases of quetiapineantidepresant effect in the bipolar disorder", Actasespanolas de psiquiatria., 38(1),2232.

[30] TatianeMaria de Lima Souza Brioschi, Simone Grigoleto Schramm,Eunice Kazue Kano, Eunice Emiko Mori Koono, Ting HuiChing, Cristina Helena dos Reis Serra, and ValentinaPorta, (2013) " Pharmacokinetics and Bioequivalence Evaluation of Cyclobenzaprine Tablets", BioMed research international .,2,2013.

[31] Neirinckx R.D., Canning L.R., Piper I.M., Nowotnik D.P., Pickett R.D., Holmes R.A., Volkert W.A., Forster A.M., Weisner P.S., Marriou J.A. and Chaplin S.B., (1987) "Technetium-99m d,1-HMPAO: A new radiopharmaceutical for SPECT imaging of regional cerebral blood perfusion" $\mathrm{J}$. Nucl. Med., 28 (2), 191.

[32] Walovitch R.C., Hill T.C., Garrity S.T., Cheesman E.H., Burgess B.A., O'Leary D.H., Watson A.D., Ganey M.V., Morgan R.A. and Williams S.J., (1989)"Characterization of technetium-99m-L,LECD for brain perfusion imaging, Part 1: Pharmacology of technetium-99m ECD in nonhuman primates" J. Nucl. Med., 30, 1892. 